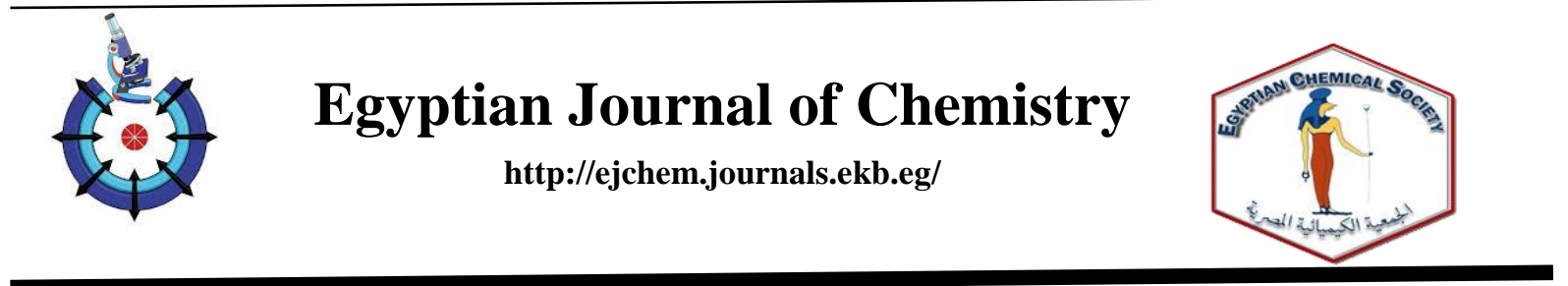

\title{
Simultaneous Quantification of Diaveridine and Sulfadimidine by Derivative and Ratio Derivative UV Spectroscopy
}

\author{
Aml M. Asran ${ }^{a}$, Nora S. Abdel Kaderb, Aida L. El-Ansary ${ }^{b}$, Sabrein H. Mohamed ${ }^{\text {b,c* }}$ \\ a First Common Year Deanship, Jouf university, P.O. Box 2014, Sakaka, Saudi Arabia. \\ $b$ Chemistry Department, Faculty of Science, Cairo University, Giza, Egypt. \\ c Chemistry Department, College of Science, Jouf University, P.O. Box 2014, Sakaka, Saudi
}

\begin{abstract}
Derivative spectrophotometry for two sulfa drugs (Diaveridine and sulfadimidine) was carried out for their simultaneous quantification in their binary mixtures. The optimum conditions were studied. The zero crossing wavelengths for Diaveridine (DV) in presence of sulfadimidine (SDM) were 235, 273, 242, 258, $244 \mathrm{~nm}, 238$ and 289, $224 \mathrm{~nm}$ for 1st, 2nd, 3rd and 4th derivatives, respectively. The linear range for DV was $2.5-35.0 \mu \mathrm{g} / \mathrm{mL}$ and that for SDM was $1.0-25.0 \mu \mathrm{g} / \mathrm{mL}$. LODs for DV were $2.32,2.50,0.76$ and $1.89 \mu \mathrm{g} / \mathrm{mL}$ with LOQs $7.73,8.33,2.55$ and $6.31 \mu \mathrm{g} / \mathrm{mL}$ for $1 \mathrm{st}, 2 \mathrm{nd}, 3 \mathrm{rd}$ and 4 th derivatives, respectively. LODs for SDM were 3.19, 2.59, 3.22 and $2.29 \mu \mathrm{g} / \mathrm{mL}$ with LOQs of $10.62,8.63,10.73$ and $7.64 \mu \mathrm{g} / \mathrm{mL}$ for $1 \mathrm{st}$, 2nd, 3rd and 4th derivatives, respectively. Moreover, ratio derivative method (1DD) was used for the quantification of both drugs; ranging from 10.0-25.0 $\mu \mathrm{g} / \mathrm{mL}$ for both drugs. 1DD values were measured at 223 and $254 \mathrm{~nm}$, for diaveridine and sulfadimidine, respectively. The obtained results were compared statistically by the Paired t-test and the variance ratio F-test.
\end{abstract}

Keywords: Diaveridine; sulfadimidine; sulfa drugs; derivative spectrophotometry.

\section{Introduction}

Sulfa drugs among several classes of pharmaceutical-antimicrobial agents are of special concern due to the conceivable formation of resistant bacterial strains [1-3]. In the veterinary field, dihydrofolate reductase inhibitors (DHFRI) for example, diaverdine (Scheme 1) act as potentiators in a mix with sulfonamides (SFA) such as sulfadimidine (Scheme 1) for the counteractive action of bacterial and protozoal diseases of animals [4, 5]. Sulfonamides are an important class of antibacterial drugs used in medicine and veterinary practice. Sulfa medications are broadly utilized in the treatment of contaminations [5-8], particularly for patients narrow minded to antibiotics. The accomplishment of these restorative specialists has made the study of sulfonamides a significant branch of research and a significance part in pharmaceutical sciences. Sulfonamides comprehensively used in the treatment of urinary tract contaminations. The official technique of British Pharmacopoeia [9], and United States Pharmacopoeia [10], depicts nitrite titration strategy for the examination of sulfa-drugs. Different techniques chromatography $[11,12]$, electro analytical methods [13-16] and spectrofluorometric [17] were used. Spectrophotometry is the most important strategy [18, 19], which has already been reported for the drug quantification as a single component [20-28]. On the basis of the overlap in the spectra of two compounds, they cannot be analyzed simultaneously by direct spectrophotometry. Derivative spectrophotometry permits the conceivable outcomes for expanding selectivity of the analytical methods without the need for prior separation and masking agent procedure [29-31]. It comprises of computing and plotting one of the

*Corresponding author e-mail: sabrein_harbi@yahoo.com.

Receive Date: 20 January 2020, Revise Date: 21 February 2020, Accept Date: 16 March 2020

DOI: 10.21608/EJCHEM.2020.22732.2353

(C2020 National Information and Documentation Center (NIDOC) 
mathematical derivatives of a spectral curve.<smiles>COc1ccc(Cc2cnc(N)nc2N)cc1OC</smiles>

Diaveridine<smiles>Cc1cc(C)nc(NS(=O)(=O)c2ccc(N)cc2)n1</smiles>

Sulfadimidine

Scheme 1. Structural formulae of diaveridine and sulfadimidine

The purpose of this work is to quantify sulfadimidine and diaverdine in their mixtures utilizing derivative spectrophotometry. The method can directly determine the cited drugs simply. The developed calibration curves were utilized in deciding the concentration of these drugs in different pharmaceutical formulations available with great accuracy and precision. This method is based on the measurements of the absolute value of the derivative spectrum of the mixture of two compounds at a wavelength value where the absorbance of one component of the mixture goes to zero. At this wavelength, the intensity is directly proportional to the other component.

The applications of derivation enable the separation of hidden signals and use them for quantitative purposes, because derivative leads to sharper zeroorder bands and gives higher signals in the resulting spectra. The spectra characteristics, for example peak height and noise level based on the parameters choice [30].

\section{Experimental}

\subsection{Apparatus}

Shimadzu 1601 double beam spectrophotometer was used for measuring the absorbance in a cuvette with an optical path length of $1 \mathrm{~cm}$, directed to an IBM-PC computer with a Lexmark printer that was utilized for absorbance signals and data treatment.

\subsection{Reagents $s$}

All reagents used throughout this study are of analytical grade. Diaveridine was obtained from El Nassr Pharmaceutical Chemicals Company, Egypt. Sulfadimidine was acquired from the Alexandria Company for Pharmaceutical and Chemical Industries, Alexandria, Egypt. Enteroquin ${ }^{\circledR}$ powder for oral suspension subjected in Amoebic and Bacillary Dysenteries and intestinal infections was obtained from the Arab Drug Company, Cairo, Egypt. New-Cox ${ }^{\circledR}$ powerful anticoccidial water soluble powder was purchased from Atco Pharama for Pharmaceutical Industry, Cairo, Egypt. While Sulfadine-K® water soluble powder was the product of United Biomid Pharama for Pharmaceutical Industry, Cairo, Egypt.

\subsection{Analysis by derivative UV spectrophotometry}

Derivative spectrophotometry method proposed by O'Haver [32] has been applied effectively for the simultaneous quantification of drugs in their mixtures. In this investigation, various orders of derivative and various types of measurements were suggested; i.e. first-, second-, third-, fourth-derivative and first ratio-spectra first derivative for the same purpose.

\subsubsection{Derivative spectrophotometric methods (1D,}

$2 D, 3 D$ and $4 D)$ for determination of diaveridine and sulfadimidine

Aliquots of $(1 \mathrm{~mL})$ from diaveridine and sulfadimidine standard working solution, equivalent to $100 \mu \mathrm{g} / \mathrm{mL}$ for both drugs, was transferred separately into two $10 \mathrm{~mL}$ volumetric flasks, and then the volume was completed with methanol. The spectra of these two solutions were scanned against a blank solution (methanol) and their absorptions were computed. The concentration of each drug was determined by constructing a calibration graph between the concentration of the drug as abscissa and 
$\mathrm{dA} / \mathrm{d} \lambda$ as ordinate at the determined zero crossing point of the other one. The 1D, 2D, 3D and 4D spectra were recorded under certain selected instrumental parameters as, $\Delta \lambda$, scaling factor and wavelength range, after that the working wavelengths of the two drugs, at the zero crossing points were recorded.

\subsubsection{Analysis by ratio spectra first order derivative $U V$ spectrophotometry}

Salinas et al. [33] introduced the technique of ratio spectra derivative spectroscopy. The decided method is based on the use of the first-derivative of the ratios of the spectra. The stored spectra of the working standard solutions of diaveridine $(2.5-35.0 \mu \mathrm{g} / \mathrm{mL})$ were divided several times by the spectrum of working standard solution of sulfadimidine each time with different concentrations $(2.5,5.0,7.5,10.0$ $\mu \mathrm{g} / \mathrm{mL}$ ) in order to obtain the most suitable concentration used as a divisor in the determination of diaveridine ratio spectra. The first derivative then was applied under certain selected instrumental parameters. The peak amplitudes were quantified, then, their values were plotted against diaveridine related concentrations. The statistical analyses of these calibration graphs were obtained using least squares method. Similarly, the stored spectra of the working standard solutions of sulfadimidine (1.0-25.0 $\mu \mathrm{g} / \mathrm{mL}$ ) were divided several times by the spectrum of working standard solution of diaveridine each time with various concentrations $(2.0,4.0,6.0,8.0,10.0$ $\mu \mathrm{g} / \mathrm{mL}$ ) after that, the first derivative was applied. The peak amplitudes were plotted against the corresponding concentrations of sulfadimidine, the statistical analyses of these calibration graphs were obtained using least squares method.

\section{Results and discussion}

\subsection{Optimization of chemical parameters}

Non polar solvents were not considered since they do not present good solubility and could become a future source of error. Different solvents were studied to develop suitable methods of analysis such as methanol, ethanol, acetone, acetonitrile, $0.1 \mathrm{~mol} / \mathrm{L}$ $\mathrm{HCl}$ and $0.1 \mathrm{~mol} / \mathrm{L} \mathrm{NaOH}$, the criteria employed were the sensitivity of the method and availability of the solvent. So that, from solvent effect studies and the spectral behavior of diaveridine and sulfadimidine, methanol was the solvent of choice for all the suggested methods owing to the high solubility of the drugs in it, and also there is no shift in their absorbance maxima in methanol. Also extraction of the drug with methanol from pharmaceutical preparations eliminates the interference from most common excipients present, under these conditions, the simultaneous determination is more effective and the sensitivity for the determination of the cited drugs is improved. Further, in this solvent both drugs are stable for at least $24 \mathrm{~h}$ which is a good feature needed for any applicable method.

\subsection{Selection of optimum apparatus conditions}

The main instrumental parameter affecting the shape of the derivative spectra is the wavelength increment over which the derivatives are obtained $(\Delta \lambda)$. This parameter needs to be optimized to give a well resolved large peak, to give good selectivity and higher sensitivity in the determination. Generally, noise decreases with an increase of $\Delta \lambda$, thus decreasing the fluctuation in a derivative spectrum. However, if the value of $\Delta \lambda$ is too large, the spectral intensity signal of the derivative deteriorates. For diaveridine and sulfadimidine when the $\Delta \lambda$ value was more than $10 \mathrm{~nm}$, the signal amplitudes decrease slightly.

The scale factor must be studied in order to observe whether the system presents a distortion effect of the spectra. Further, the selection of this parameter permits improvement of the reading of the analytical signal. By using the first derivative, the scaling factor was varied as; 2, 4, 8 and 10 , a value of 10 was selected because it presents maximum sensitivity without affecting the signal/ noise ratio. By using the second derivative, the scaling factor was varied as; $10,20,30$ and 100, a value of 100 was selected because it presents maximum sensitivity. While in the third and fourth derivative method, the measurements were done at scaling factor equal 1000 .

\subsection{Selection of optimum mathematical parameters}

Preliminary tests to optimize the method concerned, in particular, the selection of the more convenient working wavelengths. Fig. (1) shows the zero-order UV spectra of DV and SDM. It is quite clear that there is extensive spectral overlap, thus conventional UV spectrophotometry cannot be used for the individual determination of either drug in their binary mixture. The study of their derivative spectra may overcome this difficulty. 


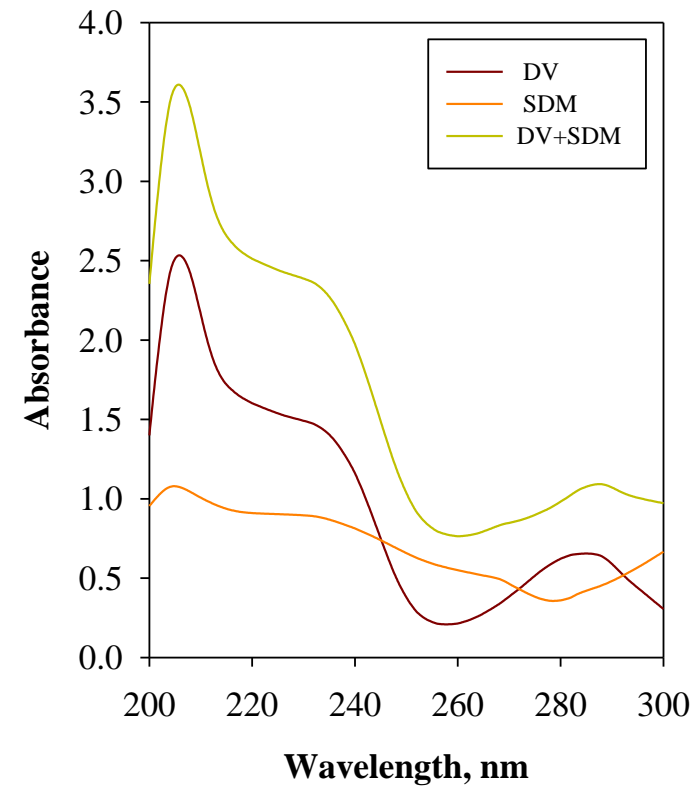

Fig. 1. Zero-order absorption spectra for $15.0 \mu \mathrm{g} / \mathrm{mL}$ DV and $10.0 \mu \mathrm{g} / \mathrm{mL} \mathrm{SDM} \mathrm{in} \mathrm{methanol} \mathrm{and} \mathrm{their}$ mixture.

\subsection{Derivative spectrophotometric methods for simultaneous determination of diaveridine and sulfadimidine}

\subsubsection{Selection of analytical wavelength}

The first order spectra of DV and SDM, also their zero crossing wavelengths were indicated in Fig. 2, a. The selected wavelength, for the determination of DV was $242 \mathrm{~nm}$; at this wavelength the amplitude is proportional to DV concentration only (zero-crossing point for SDM). On the other hand, the selected wavelength for the determination of SDM was 258 $\mathrm{nm}$, because at this wavelength SDM peaks have amplitude values while the corresponding DV peaks read zero (zero-crossing point for DV). So these wavelengths would be examined to be the optimum working wavelengths for simultaneous determination of DV and SDM in their binary mixtures.

The good resolution of the second-derivative spectra allowed selecting the optimal working wavelengths from several zero-crossing wavelengths, those which exhibited the best linear response to analyte concentration and higher sensitivity. The second-derivative spectra of DV and SDM are shown in Fig. (2, b), also their corresponding zero-crossing wavelengths were indicated in these figures. Among these, $\lambda=235 \mathrm{~nm}$ for determination of DV and $\lambda=273$ $\mathrm{nm}$ for determination of SDM were selected as working wavelengths (shown in the figure), in that measurements of the absolute value of the total derivative spectra taken at these wavelengths gave the best response to the analyte concentration.

Figure $(2, \mathrm{c})$ shows the third order (3D) spectra of DV and SDM, and also their corresponding zerocrossing wavelengths were indicated in this figure (244 $\mathrm{nm}$ for DV and $238 \mathrm{~nm}$ for SDM).

On the other hand, Fig. $(2, d)$ shows the fourth order (4D) spectra of DV and SDM, and also their corresponding zero-crossing wavelengths were indicated in this figure, it was found that the chosen zero crossing wavelengths (289 $\mathrm{nm}$ for DV and 224 $\mathrm{nm}$ for SDM) have in front peaks with maximum or near to maximum amplitudes to the other drug, similar as in 3D method.

\subsubsection{Linearity range}

The calibration graphs were constructed under the selected optimal conditions using the value of derivative amplitude versus concentration of studied compound. The analysis of these graphs was made using least squares method for the slope, intercept and correlation coefficient, the limit of detection, limit of quantification, the correlation coefficients and the range of linearity, Table 1 . For diaveridine, a linear correlation was obtained between peak amplitude and the corresponding concentration in the range of $2.5-35.0 \mu \mathrm{g} / \mathrm{mL}$, from which the linear regression equation was computed and found to be:

${ }^{1} \mathrm{D}=0.0387 \mathrm{X}+0.0125$ at $243 \mathrm{~nm}, \quad \mathrm{r}=0.9992$

${ }^{2} \mathrm{D}=0.041 \mathrm{X}+0.01 \quad$ at $235 \mathrm{~nm}, \quad \mathrm{r}=0.9992$

${ }^{3} \mathrm{D}=0.1215 \mathrm{X}-0.015 \quad$ at $244 \mathrm{~nm} \quad \mathrm{r}=0.9994$

${ }^{4} \mathrm{D}=0.0317 \mathrm{X}-0.0312 \quad$ at $289 \mathrm{~nm} \quad \mathrm{r}=0.9986$

Where $\mathrm{D}$ : is the derivative amplitude value $(\Delta \lambda / \Delta \mathrm{A}), \mathrm{X}$ : is the concentration of the drug in $\mu \mathrm{g} / \mathrm{mL}$ and $\mathrm{r}$ : is the correlation coefficient. For sulfadimidine, the optimal concentration range was $1.0-25.0 \mu \mathrm{g} / \mathrm{mL}$ and the linear regression equation is found to be:

${ }^{1} \mathrm{D}=0.0282 \mathrm{X}+0.008 \quad$ at $258 \mathrm{~nm}, \mathrm{r}=0.9998$

${ }^{2} \mathrm{D}=0.029 \mathrm{X}+0.001 \quad$ at $273 \mathrm{~nm}, \mathrm{r}=0.9998$

${ }^{3} \mathrm{D}=0.0421 \mathrm{X}-0.021 \quad$ at $238 \mathrm{~nm} \quad \mathrm{r}=0.9998$

${ }^{4} \mathrm{D}=0.034 \mathrm{X}-0.031 \quad$ at $224 \mathrm{~nm} \quad \mathrm{r}=0.9986$ 

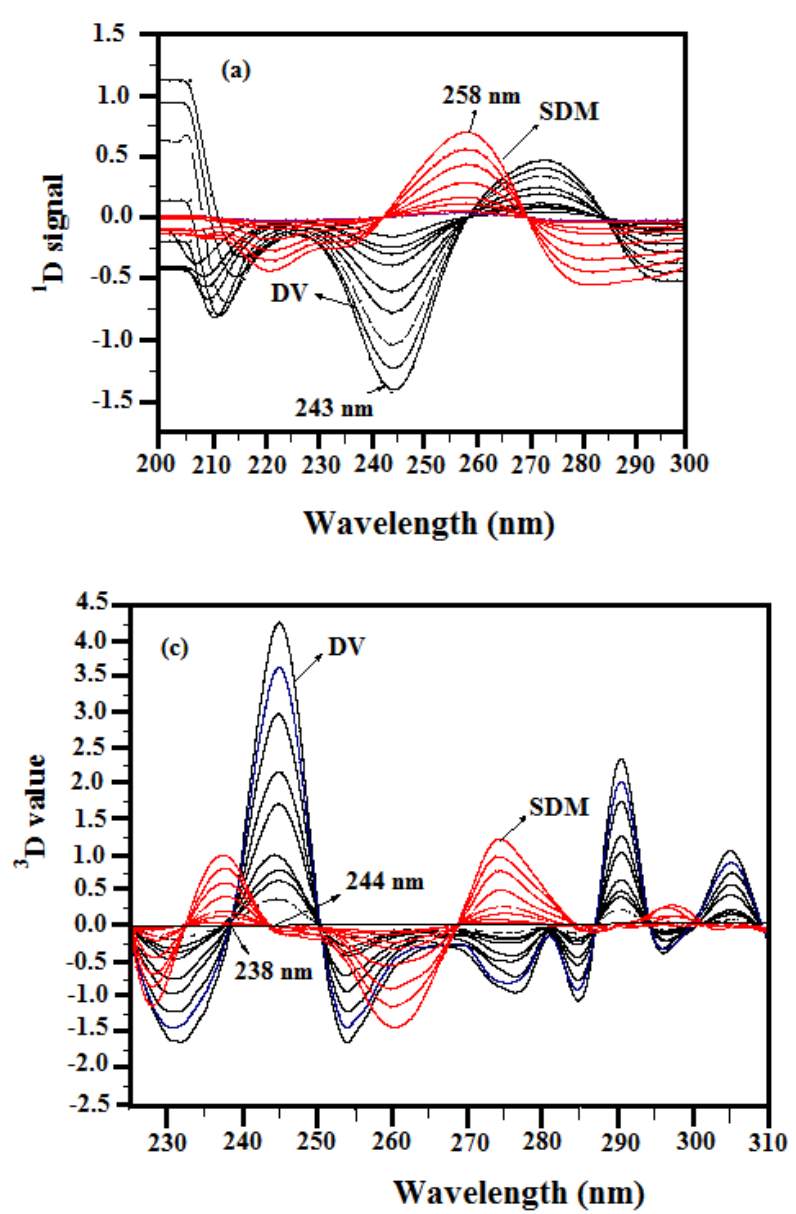

Fig. 2. (a) $1^{\text {st }}$, (b) $2^{\text {nd }}$, (c) $3^{\text {rd }}$ and (d) $4^{\text {th }}$ spectra for $2.5-35.0 \mu \mathrm{g} / \mathrm{mL} \mathrm{DV}$ and $1.0-25.0 \mu \mathrm{g} / \mathrm{mL}$ SDM in methanol

Table 1: Validation of the results obtained by applying the ${ }^{1} \mathrm{D},{ }^{2} \mathrm{D},{ }^{3} \mathrm{D}$ and ${ }^{4} \mathrm{D}$ methods.

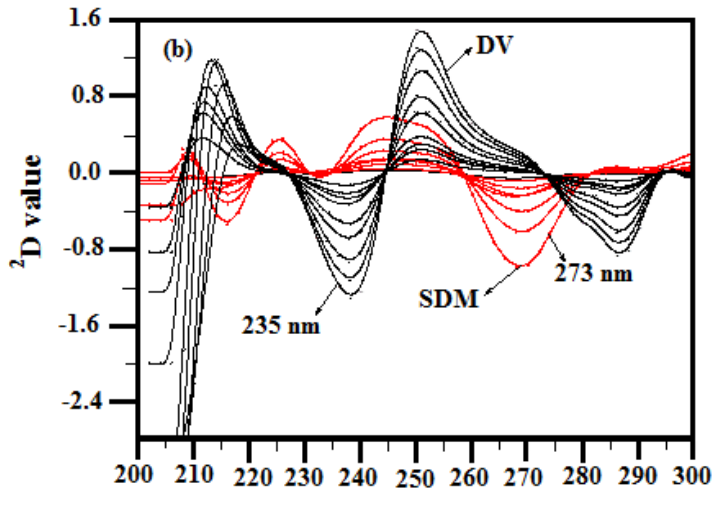

Wavelength (nm)

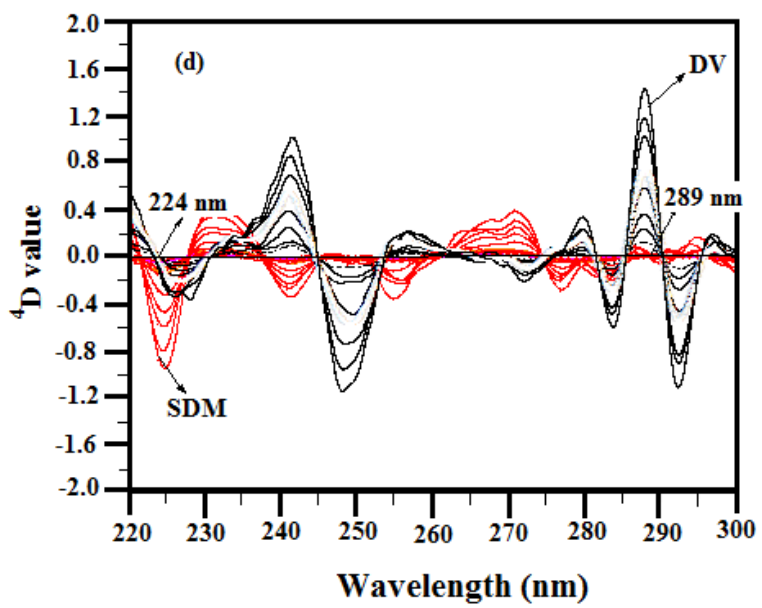

individually. It is interesting to observe the good

\begin{tabular}{|c|c|c|c|c|c|c|c|c|}
\hline \multirow[t]{2}{*}{ Parameters } & \multicolumn{4}{|l|}{ DV } & \multicolumn{4}{|l|}{ SDM } \\
\hline & ${ }^{1} \mathbf{D}$ & ${ }^{2} \mathbf{D}$ & ${ }^{3} \mathbf{D}$ & ${ }^{4} \mathrm{D}$ & ${ }^{1} \mathbf{D}$ & ${ }^{2} \mathbf{D}$ & ${ }^{3} \mathbf{D}$ & ${ }^{4} \mathbf{D}$ \\
\hline Crossing point & 242 & 235 & 244 & 289 & 258 & 273 & 238 & 224 \\
\hline $\begin{array}{r}\text { Range } \\
(\mu \mathrm{g} / \mathrm{mL})\end{array}$ & $2.5-35.0$ & $2.5-35.0$ & $2.5-35.0$ & $2.5-35.0$ & $1.0-25.0$ & $1.0-25.0$ & $1.0-25.0$ & $1.0-25.0$ \\
\hline Slope & 0.0387 & 0.030 & 0.122 & 0.0317 & 0.028 & 0.029 & 0.042 & 0.034 \\
\hline Intercept & 0.013 & 0.013 & 0.020 & $0.031-$ & 0.008 & -0.001 & $0.021-$ & $0.031-$ \\
\hline $\mathbf{r}^{2}$ & 0.9991 & 0.9998 & 0.9994 & 0.9994 & 0.9979 & 0.9996 & 0.9989 & 0.9989 \\
\hline S.D. & 0.048 & 0.030 & 0.031 & 0.020 & 0.036 & 0.027 & 0.044 & 0.026 \\
\hline $\operatorname{LOD}(\mu \mathrm{g} / \mathrm{mL})$ & 2.32 & 2.50 & 0.77 & 1.89 & 3.19 & 2.59 & 3.22 & 2.29 \\
\hline LOQ $(\mu \mathrm{g} / \mathrm{mL})$ & 7.73 & 8.33 & 2.55 & 6.31 & 10.62 & 8.63 & 10.73 & 7.64 \\
\hline S.E. & 0.234 & 0.268 & 0.204 & 0.1355 & 0.256 & 0.284 & 0.226 & 0.192 \\
\hline
\end{tabular}

In order to estimate the precision (RSD) of the method, three replicate samples included the cited drugs at different concentration levels were measured agreement between these measurements.

The accuracy of the results was checked by applying the proposed methods for determination of different blind samples of pure diaveridine and sulfadimidine.

Egypt. J. Chem. 63, No. 10 (2020) 
The concentrations were obtained from Beer's law. From which the percentage recoveries were calculated and shown in Table 2 . The good recoveries suggested good accuracy of the proposed methods, in case of determination of diaveridinein using ${ }^{1} \mathrm{D},{ }^{2} \mathrm{D}$, ${ }^{3} \mathrm{D}$ and ${ }^{4} \mathrm{D}$ methods, the mean recovery percentage values were $\left(100.45\right.$ for $\left.{ }^{1} \mathrm{D}\right),\left(100.64{ }^{2} \mathrm{D}\right),(100.33$ for $\left.{ }^{3} \mathrm{D}\right)$ and $\left(100.55\right.$ for $\left.{ }^{4} \mathrm{D}\right)$, from this we can deduce that $3 \mathrm{D}$ method is the most suitable for determination of diaveridine, on the other hand, in case of determination of sulfadimidine, the mean recovery percentage values were $\left(100.52\right.$ for $\left.{ }^{1} \mathrm{D}\right),(100.63$ for $\left.{ }^{2} \mathrm{D}\right),\left(100.48\right.$ for $\left.{ }^{3} \mathrm{D}\right)$ and $\left(100.71\right.$ for $\left.{ }^{4} \mathrm{D}\right)$, it means that ${ }^{3} \mathrm{D}$ method is also the most suitable for determination of sulfadimidine, Table 2. The recovery was calculated using the following equation:

$$
\text { Recovery }=\frac{\text { Found concentration }}{\text { Taken concentration }} \times 100
$$

\subsection{Determination of diaveridine and sulfadimidine in laboratory prepared binary mixtures using ${ }^{l} D,{ }^{2} D$, ${ }^{3} \mathrm{D}$ and ${ }^{4} \mathrm{D}$ methods (selectivity)}

The proposed method was used for determination of diaveridine in presence of sulfadimidine in different laboratory prepared mixtures without prior separation. For this purpose, a series of binary mixtures of diaveridine and sulfadimidine was prepared. The first one concentration level varied from $10-30 \mu \mathrm{g} / \mathrm{mL}$, the second one varied in the range $5.0-25.0 \mu \mathrm{g} / \mathrm{mL}$, In order to estimate the precision of the method and the homogeneity of the results, three replicate determinations of various binary mixtures of diaveridine and sulfadimidine were measured. The relative standard deviation values were calculated for each mixture. In order to estimate the accuracy of the method and reproducibility of the results, the recovery test was performed using the cited synthetic mixtures. The results were listed (Table 3 ), the results indicated that, in case of determination of diaveridine in laboratory papered binary mixtures using ${ }^{1} \mathrm{D},{ }^{2} \mathrm{D},{ }^{3} \mathrm{D}$ and ${ }^{4} \mathrm{D}$ methods, the recovery values varied in range (100.33-100.66 for $\left.{ }^{1} \mathrm{D}\right),\left(100.35-100.88\right.$ for $\left.{ }^{2} \mathrm{D}\right)$, (99.92-100.50 for $\left.{ }^{3} \mathrm{D}\right)$ and $\left(99.80-100.80\right.$ for $\left.{ }^{4} \mathrm{D}\right)$, from this we can deduce that ${ }^{3} \mathrm{D}$ method is the most suitable for determination of diaveridine in binary mixtures, but in case of determination of sulfadimidine in the same binary mixtures, the recovery percent values varied in range (100.30100.66 for $\left.{ }^{1} \mathrm{D}\right),\left(100.60-101.10\right.$ for $\left.{ }^{2} \mathrm{D}\right),(99.40-100.50$ for ${ }^{3} \mathrm{D}$ ) and (99.80-100.70 for $\left.{ }^{4} \mathrm{D}\right)$, it means that ${ }^{3} \mathrm{D}$ method is also the most suitable for determination of sulfadimidine in binary mixtures.

\subsection{Applications for determination of diaveridine and sulfadimidine in pharmaceutical preparation using the proposed methods}

The applicability of the proposed methods has been tested on commercially available pharmaceutical formulations such as New-Cox ${ }^{\circledR}$ and Sulfadine- $\mathrm{K}^{\circledR}$. The concentration of the drugs in the dosage forms was calculated from the appropriate calibration graphs. There was no shift in the working wavelengths or amplitude of the signals due to the presence of other constituents of the dosage forms. Table 4 shows the results obtained for the determination of diaveridine and sulfadimidine in the dosage forms. As can be seen, the agreement between calculated and experimental values is good; also we find that the recovery studies indicated that the excipients in the drug forms did not interfere in the determinations because these methods estimate each component independently. In addition, the estimated drugs content with low values of standard deviation further established the precision and the accuracy of the assaying methods. The results obtained were compared statistically by the Student's t-test (for accuracy) and the variance ratio F-test (for precision) with those obtained by the reported method [34, 35], Table 4 . The values of $\mathrm{t}$ - and F-tests obtained at $95 \%$ confidence level did not exceed the theoretical tabulated value indicating no significant difference between the methods compared. From this we can deduce that, the developed methods may be recommended for routine and quality control analysis of the investigated drugs to provide simple, accurate and reproducible quantitative analysis for determination of diaveridine and sulfadimidine in bulk powder and pharmaceutical formulations.

Table 2: Accuracy of the determination of diaveridine or sulfadimidine by applying the proposed derivative methods. 


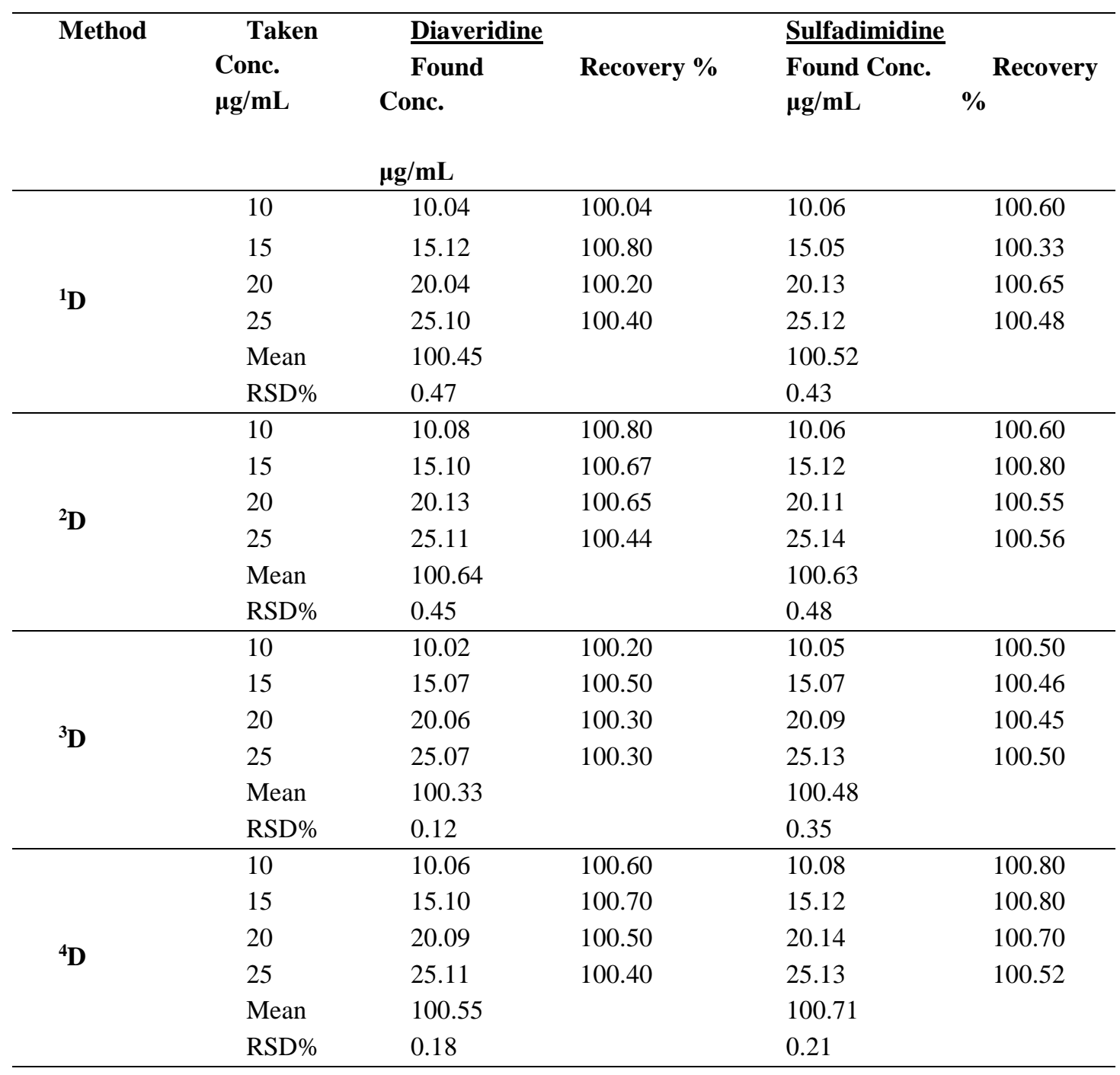


Table 3: Analysis of laboratory prepared mixtures contains different concentration ratios of diaveridine and sulfadimidine for the determination of diaveridine and sulfadimidine using ${ }^{1} \mathrm{D},{ }^{2} \mathrm{D},{ }^{3} \mathrm{D}$ and ${ }^{4} \mathrm{D}$ methods

\begin{tabular}{|c|c|c|c|c|c|c|c|c|c|}
\hline \multicolumn{3}{|c|}{ Taken Conc. $\mu \mathrm{g} / \mathrm{mL}$} & \multicolumn{2}{|l|}{${ }^{1} D$} & \multicolumn{2}{|l|}{${ }^{2} \mathbf{D}$} & \multirow{2}{*}{$\begin{array}{c}{ }^{3} \mathrm{D} \\
\text { Recovery } \\
\%\end{array}$} & \multicolumn{2}{|c|}{${ }^{4} \mathrm{D}$} \\
\hline DV & SDM & $\begin{array}{l}\text { Found } \\
\text { Conc. } \\
\mu \mathrm{g} / \mathrm{mL}\end{array}$ & $\begin{array}{c}\text { Recovery } \\
\%\end{array}$ & $\begin{array}{l}\text { Found Conc } \\
\mu \mathrm{g} / \mathrm{mL}\end{array}$ & $\begin{array}{c}\text { Recovery } \\
\%\end{array}$ & $\begin{array}{l}\text { Found } \\
\text { Conc. } \\
\mu \mathrm{g} / \mathrm{mL}\end{array}$ & & $\begin{array}{l}\text { Found } \\
\text { Conc. } \\
\mu \mathrm{g} / \mathrm{mL}\end{array}$ & $\begin{array}{c}\text { Recovery } \\
\%\end{array}$ \\
\hline \multicolumn{10}{|c|}{ Diaveridine } \\
\hline$\overline{10}$ & 25 & 10.04 & 100.4 & 10.04 & 100.4 & 10.05 & 100.5 & 10.09 & 100.9 \\
\hline 10 & 20 & 10.06 & 100.6 & 10.06 & 100.6 & 10.04 & 100.4 & 10.08 & 100.8 \\
\hline 15 & 20 & 15.05 & 100.3 & 15.09 & 100.6 & 15.07 & 100.5 & 15.11 & 100.7 \\
\hline 20 & 20 & 20.12 & 100.6 & 20.17 & 100.9 & 20.09 & 100.5 & 20.07 & 100.4 \\
\hline 20 & 15 & 20.11 & 100.6 & 20.13 & 100.7 & 20.08 & 100.4 & 19.96 & 99.8 \\
\hline 20 & 10 & 20.09 & 100.5 & 20.07 & 100.4 & 20.05 & 100.3 & 19.98 & 99.9 \\
\hline 25 & 10 & 25.12 & 100.5 & 25.22 & 100.9 & 24.98 & 99.9 & 25.11 & 100.4 \\
\hline \multicolumn{10}{|c|}{ Sulfadimidine } \\
\hline 25 & 10 & 10.06 & 100.6 & 10.06 & 100.6 & 9.94 & 99.4 & 10.01 & 100.1 \\
\hline 20 & 10 & 10.03 & 100.3 & 10.11 & 101.1 & 10.05 & 100.5 & 10.02 & 100.2 \\
\hline 20 & 15 & 15.05 & 100.3 & 15.14 & 100.90 & 15.08 & 100.5 & 15.04 & 100.3 \\
\hline 20 & 20 & 20.07 & 100.4 & 20.19 & 101.0 & 19.97 & 99.9 & 20.14 & 100.7 \\
\hline 15 & 20 & 20.10 & 100.5 & 20.16 & 100.8 & 20.07 & 100.4 & 20.06 & 100.3 \\
\hline 10 & 20 & 20.08 & 100.4 & 20.10 & 100.5 & 20.09 & 100.5 & 20.09 & 100.5 \\
\hline 10 & 25 & 25.13 & 100.5 & 25.18 & 100.7 & 25.11 & 100.4 & 24.95 & 99.8 \\
\hline
\end{tabular}

3.7. First derivative ratio spectra $\left({ }^{1} D D\right)$ method for the simultaneous determination of diaveridine and sulfadimidine in a binary mixture

Ratio spectra derivative spectrophotometry offers greater selectivity than the conventional spectrophotometry for simultaneous determination of the two drugs in a mixture without pervious chemical separation; it also has a great ability to resolve mixture of compounds exhibiting highly overlapped spectra successfully with high selectivity and accuracy. The absorption spectrum of the mixture is obtained anv vd divided (amplitude by amplitude at appropriate wavelengths) by the absorption spectrum of a standard solution of one of the components (previously stored in a computer), and the derivative of the ratio spectrum is obtained.

In this part, first derivative of ratio spectrophotometric method $\left({ }^{1} \mathrm{DD}\right)$ was proposed for the simultaneous determination of sulfadimidine and diaveridine in a binary mixture and to eliminate any spectral overlap with high selectivity, sensitivity and accuracy, the ratio spectra of diaveridine was obtained by dividing its absorption spectra by the absorption spectrum of a certain concentration of sulfadimidine. Similarly, the ratio spectra of sulfadimidine had been obtained by dividing its absorption spectra by the absorption spectrum of a certain concentration of diaveridine and then the first derivative of the obtained ratio spectra of sulfadimidine and diaveridine, separately, can be obtained easily.

To optimize the ${ }^{1} \mathrm{DD}$ method for determination of diaveridine and sulfadimidine in their binary mixture we have first study the influence of certain variables on the derivative ratio spectra such as: divisor concentration, $\Delta \lambda$ and scaling factor (SF).

\subsubsection{The effect of divisor concentrations}

The stored spectra of working standard solution of diaveridine $(2.5-35 \mu \mathrm{g} / \mathrm{mL})$ were divided several times by the spectrum of working standard solution

Egypt. J. Chem. 63, No. 10 (2020) 
of sulfadimidine each time with different concentrations $(2.0,4.0,6.0,8.0$ and $10.0 \mu \mathrm{g} / \mathrm{mL})$ in order to obtain the most suitable concentration used as a divisor in the determination of diaveridine ratio spectra. The second divisor $(4.0 \mu \mathrm{g} / \mathrm{mL})$ was found the best regarding it has a good signal to noise ratio with good slope and intercept values and more repeatable results. Fig. (3, A) shows ratio spectra of different concentrations of DV $(2.5-35.0 \mu \mathrm{g} / \mathrm{mL})$ divided by zero-order absorption spectrum of SDM $(4.0 \mu \mathrm{g} / \mathrm{mL})$.

Table 4: The analysis of diaveridine ${ }^{\mathrm{a}}$ and sulfadimidine ${ }^{b}$ in pharmaceutical dosage forms by the proposed ${ }^{1} \mathrm{D},{ }^{2} \mathrm{D},{ }^{3} \mathrm{D}$ and ${ }^{4} \mathrm{D}$ methods plotted against the corresponding concentrations of diaveridine, the statistical analyses of these calibration graphs were obtained using least squares method. Similarly, the stored spectra of the working standard solutions of sulfadimidine $(1.0-25.0 \mu \mathrm{g} / \mathrm{mL})$ were divided several times by the spectrum of working standard solution of diaveridine each time with different concentrations (1.0, 2.5, 5.0, 7.5 and $10.0 \mu \mathrm{g} / \mathrm{mL}$ ) in order to obtain the most suitable concentration used as a divisor in the determination of sulfadimidine ratio spectra, It was found that the first derivative of ratio spectra (1DD) method was

\begin{tabular}{|c|c|c|c|c|c|c|c|c|c|}
\hline \multirow{2}{*}{$\begin{array}{l}\text { Dosage } \\
\text { Forms }\end{array}$} & \multirow{2}{*}{$\begin{array}{c}\text { Taken } \\
\mu \mathrm{g} / \mathrm{mL}\end{array}$} & \multicolumn{2}{|c|}{${ }^{1} \mathbf{D}$} & \multicolumn{2}{|c|}{${ }^{2} \mathbf{D}$} & \multicolumn{2}{|c|}{${ }^{3} \mathbf{D}$} & \multicolumn{2}{|c|}{${ }^{4} \mathbf{D}$} \\
\hline & & Found ${ }^{*} \mu \mathrm{g} / \mathrm{mL}$ & Recovery \% & Found ${ }^{*} \mu \mathrm{g} / \mathrm{mL}$ & Recovery \% & Found ${ }^{*} \mu \mathrm{g} / \mathrm{mL}$ & Recovery \% & Found ${ }^{*} \mu \mathrm{g} / \mathrm{mL}$ & Recovery \% \\
\hline \multirow[t]{3}{*}{ New-Cox ${ }^{a}$} & 10 & 10.16 & 101.6 & 9.82 & 98.2 & 10.14 & 101.4 & 10.16 & 101.6 \\
\hline & 15 & 15.15 & 101.0 & 14.88 & 99.2 & 15.17 & 101.1 & 15.15 & 101.0 \\
\hline & 20 & 20.16 & 100.8 & 19.88 & 99.4 & 20.15 & 100.8 & 20.16 & 100.8 \\
\hline t-test & \multicolumn{3}{|c|}{1.06} & \multicolumn{2}{|c|}{0.97} & \multicolumn{2}{|c|}{1.06} & \multicolumn{2}{|c|}{2.01} \\
\hline F-test & \multicolumn{3}{|c|}{1.78} & \multicolumn{2}{|c|}{1.54} & \multicolumn{2}{|c|}{1.78} & \multicolumn{2}{|c|}{3.19} \\
\hline \multirow[t]{3}{*}{$\begin{array}{c}\text { Sulfadine- } \\
\mathbf{K}^{\mathbf{b}}\end{array}$} & 10 & 10.27 & 102.7 & 10.29 & 102.9 & 10.09 & 100.9 & 10.07 & 100.7 \\
\hline & 15 & 15.26 & 101.7 & 15.26 & 101.7 & 15.04 & 101.3 & 15.09 & 100.6 \\
\hline & 20 & 20.26 & 101.3 & 20.25 & 101.3 & 20.12 & 101.6 & 20.16 & 100.8 \\
\hline t-test & \multicolumn{3}{|c|}{2.04} & \multicolumn{2}{|c|}{1.77} & \multicolumn{2}{|c|}{2.04} & \multicolumn{2}{|c|}{1.94} \\
\hline F-test & \multicolumn{3}{|c|}{2.21} & \multicolumn{2}{|c|}{2.96} & \multicolumn{2}{|c|}{2.12} & \multicolumn{2}{|c|}{3.24} \\
\hline \multirow[t]{3}{*}{ Entroqeen $^{b}$} & 10 & 10.25 & 102.5 & 10.26 & 102.6 & 9.95 & 99.5 & 10.15 & 101.5 \\
\hline & 15 & 14.82 & 98.8 & 15.21 & 101.4 & 14.82 & 98.8 & 15.17 & 101.1 \\
\hline & 20 & 20.25 & 101.25 & 19.87 & 99.4 & 19.89 & 99.5 & 20.15 & 100.8 \\
\hline t-test & \multicolumn{3}{|c|}{1.15} & \multicolumn{2}{|c|}{1.29} & \multicolumn{2}{|c|}{1.96} & \multicolumn{2}{|c|}{2.03} \\
\hline F-test & \multicolumn{3}{|c|}{2.13} & \multicolumn{2}{|c|}{3.24} & \multicolumn{2}{|c|}{2.25} & \multicolumn{2}{|c|}{2.52} \\
\hline
\end{tabular}

The first derivative then was applied under certain selected instrumental parameters $\Delta \lambda=4$, scaling factor $\mathrm{SF}=1$ and wavelength range $(220-350 \mathrm{~nm})$. The peak amplitudes were measured and their values were applied by choosing the concentration of 7.5 $\mu \mathrm{g} / \mathrm{mL}$ as convenient divisor concentration where it has a good signal to noise ratio with good slope and 
intercept values and more repeatable results, the curves are shown in Fig. (3, B).

The first derivative then was applied under certain selected instrumental parameters $\Delta \lambda=8$, scaling factor $\mathrm{SF}=1$ and wavelength range $(220-350 \mathrm{~nm})$. The peak amplitudes were measured and their values were plotted against the corresponding concentrations of sulfadimidine, the statistical analyses of these calibration graphs were obtained using least squares method. plotting the peak amplitudes at the selected wavelengths versus concentration of the studied drugs.

For diaveridine, a linear correlation was obtained between peak amplitude and the corresponding concentration in the range of $2.5-35.0 \mu \mathrm{g} / \mathrm{mL}$, where that for sulfadimidine, was $1.0-25.0 \mu \mathrm{g} / \mathrm{mL}$.

The validation of ${ }^{1} \mathrm{DD}$ method for the determination of diaveridine and sulfadimidine in a binary mixture was applied by choosing the working

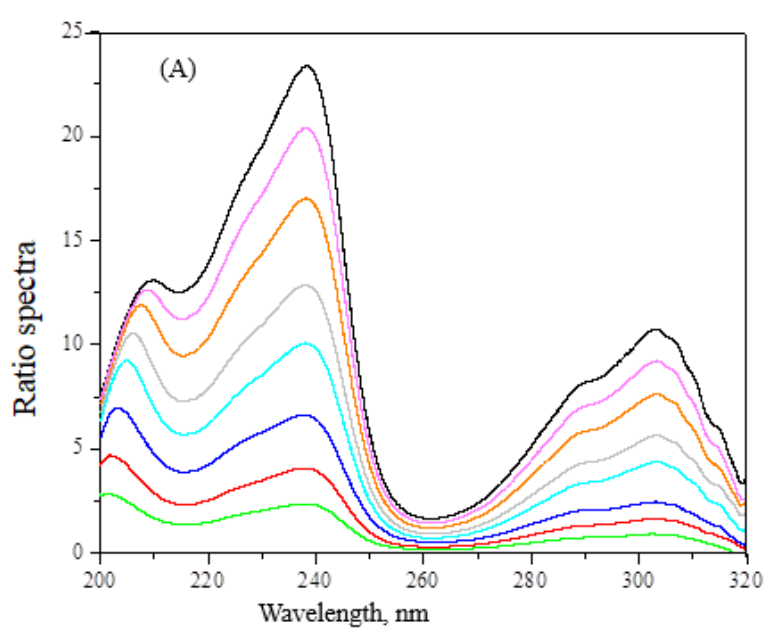

Fig 3. Ratio spectra of different concentrations of DV $(2.5-35.0 \mu \mathrm{g} / \mathrm{mL})$ divided by zero-order absorption spectrum of SDM $(4.0 \mu \mathrm{g} / \mathrm{mL}),(\mathrm{A})$ and ratio spectra of different concentrations of SDM $(2.5-35.0 \mu \mathrm{g} / \mathrm{mL})$ divided by zero-order absorption spectrum of $\mathrm{DV}$ (7.5 $\mu \mathrm{g} / \mathrm{mL}),(\mathrm{B})$.

\subsubsection{Selection of analytical wavelengths}

Figure (4) shows the first derivative ratio ( $\left.{ }^{1} \mathrm{DD}\right)$ spectra of diaveridine and sulfadimidine, also their corresponding zero-crossing wavelengths were indicated in these figures. These wavelengths achieved the more accurate, reproducible and sensitive results, so they would be examined to be the optimum working wavelengths for the simultaneous determination of diaveridine and sulfadimidine in binary mixtures using the first derivative ratio $\left({ }^{1} \mathrm{DD}\right)$ method.

\subsubsection{Linearity range}

Under the experimental conditions, by applying 1DD method, calibration curves were constructed by

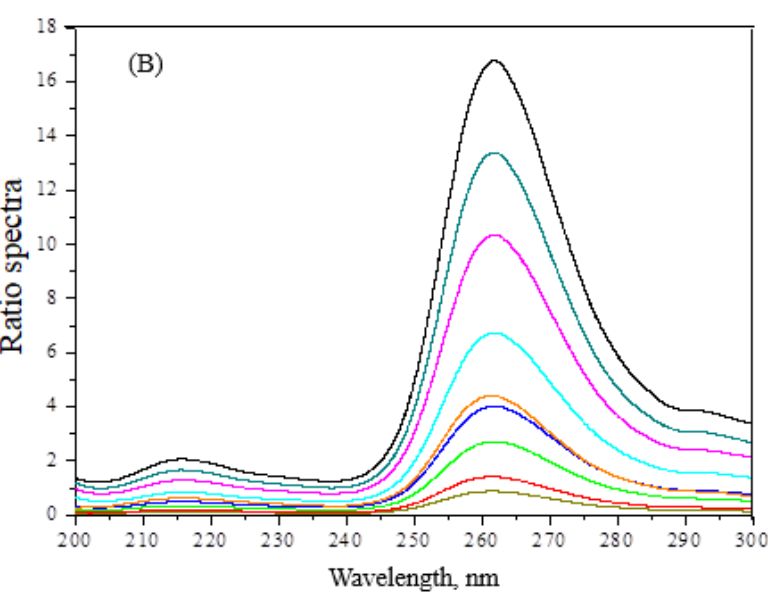

wavelengths (223 and $245 \mathrm{~nm}$ for DV and 254 and $271 \mathrm{~nm}$ for SDM), where they have the most suitable values of the regression equations parameters, the analytical data at these wavelengths were grouped in Table 5, the limit of detection and limit of quantification were determined according to $\mathrm{ICH}$ recommendations [34] which are also grouped in Table 5 .

Table 5 : Validation of the results obtained by applying the first derivative ratio method ( $\left.{ }^{1} \mathrm{DD}\right)$.

\begin{tabular}{lllll}
\hline \multirow{2}{*}{ Parameters } & \multicolumn{2}{l}{ Diaveridine } & \multicolumn{2}{l}{ Sulfadimidine } \\
\cline { 2 - 5 } & $\boldsymbol{\lambda} \mathbf{2 2 3} \mathbf{n m}$ & $\boldsymbol{\lambda} \mathbf{2 4 5} \mathbf{~ n m}$ & $\boldsymbol{\lambda}_{\mathbf{2 5 4}} \mathbf{~ n m}$ & $\boldsymbol{\lambda}_{\mathbf{2 7 1} \mathbf{~} \mathbf{m}}$ \\
\hline Range $(\boldsymbol{\mu} \mathbf{g} / \mathbf{m L})$ & $2.5-35$ & $2.5-35$ & $1-25$ & $1-25$ \\
Slope & 0.059 & -0.063 & 0.045 & -0.028 \\
Intercept & -0.009 & -0.18 & 0.009 & -0.007 \\
$(\mathbf{r})$ & 0.9996 & 0.9989 & 0.9996 & 0.9994 \\
S.D. & 0.039 & 0.024 & 0.036 & 0.032 \\
LOD $(\boldsymbol{\mu g} / \mathbf{m L})$ & 1.97 & 1.142 & 2.35 & 3.24 \\
LOQ $(\boldsymbol{\mu g} / \mathbf{m L})$ & 6.58 & 3.81 & 7.83 & 11.42 \\
S.E. & 0.198 & 0.209 & 0.188 & 0.212 \\
\hline
\end{tabular}

Egypt. J. Chem. 63, No. 10 (2020) 


\subsubsection{Determination of diaveridine and sulfadimidine in bulk powder using ${ }^{1} D D$ method}

The accuracy of the proposed method was determined by investigation the percentage recovery at four concentration levels, each in triplicate, ranging from $10.0-25.0 \mu \mathrm{g} / \mathrm{mL}$ for both drugs. ${ }^{1} \mathrm{DD}$ values were measured at 223 and $254 \mathrm{~nm}$, for diaveridine and sulfadimidine, respectively. The concentrations were obtained from Beer's law. The percentage recoveries were calculated and shown in Table 6. In determination diaveridine and sulfadimidine the mean recovery value was $100.3 \%$. The obtained results indicated the agreement between them and those accepted as true. The good recoveries suggested good accuracy of the proposed methods.

Table 6: Analysis of laboratory prepared mixtures contains different concentration ratios of $\mathrm{DV}$ and SDM for the determination of diaveridine using 1DD method

\begin{tabular}{|c|c|c|c|c|c|c|}
\hline \multirow{2}{*}{\multicolumn{3}{|c|}{$\begin{array}{c}\text { Taken Conc. } \\
\mu \mathrm{g} / \mathrm{mL}\end{array}$}} & \multicolumn{2}{|c|}{ DV } & \multicolumn{2}{|c|}{ SDM } \\
\hline & & & \multirow{2}{*}{$\begin{array}{l}\text { Found } \\
\text { Conc. } \\
\mu \mathrm{g} / \mathrm{mL}\end{array}$} & \multirow{2}{*}{$\begin{array}{c}\text { Recovery } \\
\%\end{array}$} & \multirow{2}{*}{$\begin{array}{l}\text { Found } \\
\text { Conc. } \\
\mu \mathrm{g} / \mathrm{mL}\end{array}$} & \multirow{2}{*}{$\begin{array}{c}\text { Recovery } \\
\%\end{array}$} \\
\hline DV & SDM & DV\% & & & & \\
\hline 10 & 25 & 40 & 10.05 & 100.5 & 10.04 & 100.4 \\
\hline 10 & 20 & 50 & 10.03 & 100.3 & 10.07 & 100.7 \\
\hline 15 & 20 & 75 & 20.07 & 100.4 & 15.09 & 100.6 \\
\hline 20 & 20 & 100 & 20.06 & 100.3 & 19.98 & 99.9 \\
\hline 20 & 15 & 133 & 19.96 & 99.8 & 20.04 & 100.2 \\
\hline 20 & 10 & 200 & 19.93 & 99.7 & 20.06 & 100.3 \\
\hline 25 & 10 & 250 & 24.97 & 99.9 & 25.05 & 100.2 \\
\hline
\end{tabular}

\subsubsection{Determination of diaveridine and sulfadimidine in laboratory papered binary mixtures using ${ }^{I} D D$ method (selectivity).}

The proposed method used for determination of diaveridine in presence of sulfadimidine in different laboratory prepared mixtures without prior separation. For this purpose, a series of binary mixtures of diaveridine and sulfadimidine was prepared. The concentration level of the two drugs varied from $10-25 \mu \mathrm{g} / \mathrm{mL}, 1 \mathrm{DD}$ values were measured at 223 and $254 \mathrm{~nm}$, for diaveridine and sulfadimidine, respectively. Then the concentrations of diaveridine and sulfadimidine were calculated from the corresponding regression equations. In order to estimate the precision of the method and the homogeneity of the results, three replicate determinations of various binary mixtures of diaveridine and sulfadimidine were measured. The relative standard deviation values were calculated for each mixture. In order to estimate the accuracy of the method and reproducibility of the results, the recovery values $\%$ were calculated for the cited synthetic mixtures. The results were listed at Table 6.

\subsubsection{Applications for determination of diaveridine and sulfadimidine in pharmaceutical preparation using ${ }^{1} D D$ method).}

The applicability of the proposed methods has been tested on commercially available pharmaceutical formulations such as New-Cox $\square$ and Sulfadine-K $\square$, three replicate determinations were made.1DD values were measured at 223 and $254 \mathrm{~nm}$, for diaveridine and sulfadimidine, respectively. Satisfactory results were obtained for diaveridine and sulfadimidine and were in a good agreement with label claims. The results obtained were compared statistically by the Student's t-test (for accuracy) and the variance ratio F-test (for precision) with those obtained by the reported method $[35,36]$, Table 7 . The values of $t-$ and F-tests obtained at $95 \%$ confidence level did not exceed the theoretical tabulated value 2.306 and 6.39 indicating no significant difference between the performance of these methods regarding their accuracy and precision.

However, the derivative spectrophotometry technique was adopted in order to determine binary mixture of constituents, because it is a reliable technique which does not require complex processing of mathematical data. Therefore, it is much easier to apply than the numerical type method; the investigated methods were further validated by estimation of diaveridine and sulfadimidine in different pharmaceutical formulations, there is no interference from the formulation matrix present in the studied formulations. 

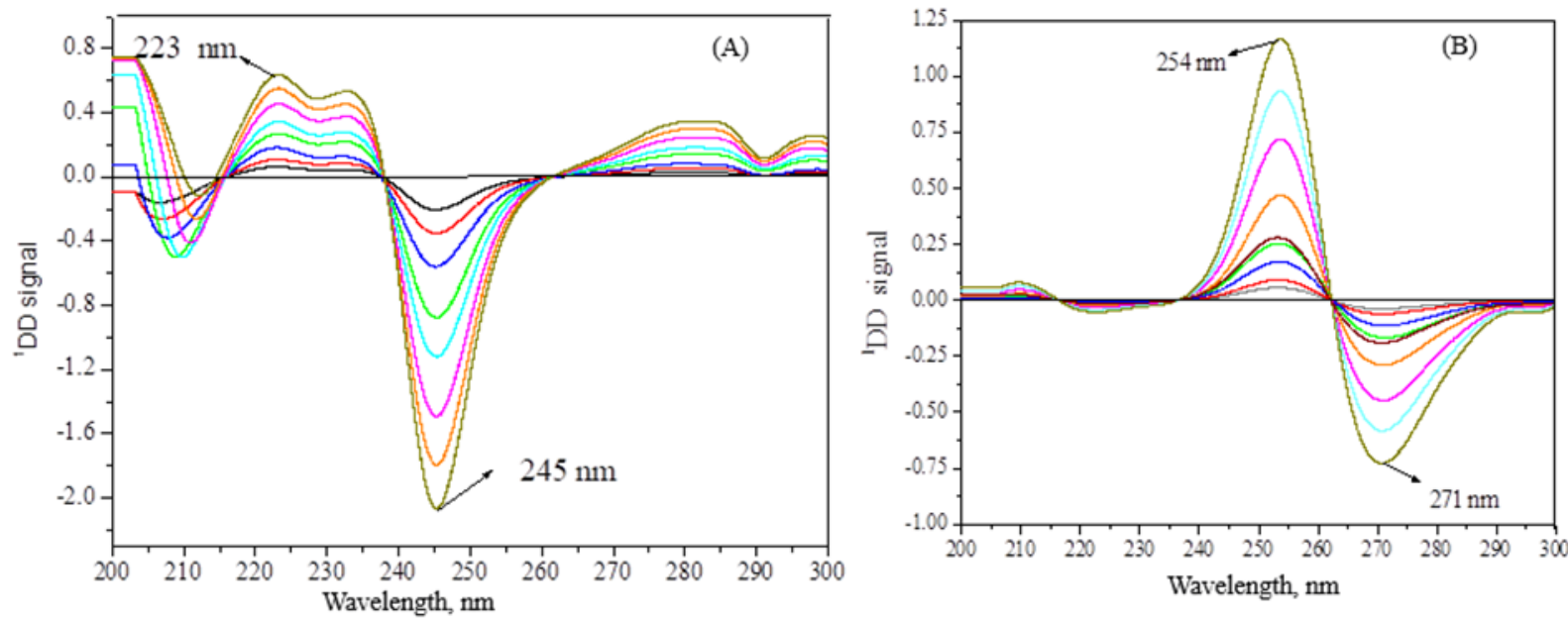

Fig. 4. First-derivative ratio spectra for DV (2.5-35.0 $\mu \mathrm{g} / \mathrm{mL})(\mathrm{A})$, and for SDM $(1.0-25.0 \mu \mathrm{g} / \mathrm{mL})(B)$ in methanol.

Table 7: The analysis of diaveridine ${ }^{a}$ and sulfadimidine $^{\mathrm{b}}$ in pharmaceutical dosage forms by the proposed ${ }^{1} \mathrm{DD}$ method.

\begin{tabular}{|c|c|c|c|c|c|c|}
\hline $\begin{array}{l}\text { Pharmaceutical } \\
\text { dosage forms }\end{array}$ & $\begin{array}{l}\text { Taken } \\
(\mu \mathrm{g} / \mathrm{mL})\end{array}$ & $\begin{array}{l}\text { Found* } \\
(\mu \mathrm{g} / \mathrm{mL})\end{array}$ & Recovery \% & $\begin{array}{l}\text { Relative } \\
\text { error } \\
(\%)\end{array}$ & $\begin{array}{l}\text { t- } \\
\text { test }\end{array}$ & $\begin{array}{l}\text { F- } \\
\text { test }\end{array}$ \\
\hline \multirow[t]{3}{*}{ New -Cox ${ }^{\circledR a}$} & 10 & 10.07 & 100.70 & 0.70 & \multirow{3}{*}{0.69} & \multirow{3}{*}{0.52} \\
\hline & 15 & 15.08 & 100.50 & 0.50 & & \\
\hline & 20 & 20.05 & 100.25 & 0.25 & & \\
\hline \multirow[t]{3}{*}{ Sulfadine-K ${ }^{\circledR b}$} & 10 & 10.07 & 100.70 & 0.90 & \multirow{3}{*}{1.14} & \multirow{3}{*}{1.87} \\
\hline & 15 & 15.03 & 100.20 & 0.26 & & \\
\hline & 20 & 20.09 & 100.45 & 0.60 & & \\
\hline \multirow[t]{3}{*}{ Entroqeen $^{\circledR b}$} & 10 & 10.01 & 100.10 & 0.50 & \multirow{3}{*}{0.98} & \multirow{3}{*}{1.07} \\
\hline & 15 & 15.07 & 100.47 & 1.20 & & \\
\hline & 20 & 20.04 & 100.20 & 0.55 & & \\
\hline
\end{tabular}

4.

\section{Conclusions}

The main task of this study is to find fast, accurate, sensitive and cost effective spectrophotometric techniques for the simultaneous determination of diaveridine and sulfadimidine in pure forms and in some commercial pharmaceutical preparations. It is based on derivative spectrophotometry, first, second, third, fourth and first ratio derivative spectra of binary mixtures containing diaveridine and sulfadimidine were established. The results were in a good linearity with negligible intercepts, the high values of correlation coefficients indicate the good linearity of all calibration graphs and the validity of Beer's law to

Egypt. J. Chem. 63, No. 10 (2020) 
derivative measurements. Satisfactory results were obtained for the recovery of each drug in the mixtures. From recovery studies, ${ }^{1} \mathrm{DD}$ and ${ }^{3} \mathrm{D}$ methods are the most suitable for determination of sulfadimidine and diaveridine in binary mixtures. The proposed methods are selective and sensitive for simultaneous determination of the drugs.

\section{Conflicts of interest}

There is no conflict of interest.

\section{Formatting of funding sources}

No funding sources

\section{References}

[1] Senta I., Terzic S. and Ahel M., Simultaneous determination of sulfonamides, fluoroquinolones, macrolides and trimethoprim in wastewater and river water by LC-TandemMS. J. Chromatographia 68, 747-758 (2008).

[2] Feng J., Zhang S., Shi W. and Zhang Y., Activity of sulfa drugs and their combinations against stationary phase B. burgdorferi In Vitro. Antibiotics 6, 1-11, (2017).

[3] Synthesis, characterization and biological evaluation studies of 4-((3-Formyl-4-hydroxyphenyl) diazinyl) - $\mathrm{N}$-(4-methyloxazol-2-yl) benzene sulfonamide with $\mathrm{Cu}(\mathrm{II})$, $\mathrm{Ni}$ (II), $\mathrm{Zn}(\mathrm{II})$ and $\mathrm{Ag}(\mathrm{I})$ using a microwave irradiation, Egypt. J. Chem. 61 (4), 569 - 580 (2018).

[4] Rehm W.F., Teeimann K., Weidekamm E. and Rico A.G., Drug residues in animals, academic, Orlando, FL, USA, Ch. 4 (1986).

[5] Lemnge M.M., Ronn A., Flach H. and Bygbjerg I.C., Simultaneous determination of dapsone, monoacetyldapsone and pyrimethamine in whole blood and plasma by highperformance liquid chromatography, J. Chromatogr. B 613, 340-346 (1993)

[6] Tačić A., Nikolić V., Nikolić L. and Savić I., Antimicrobial sulfonamide drugs. Advanced technologies, 6(1), 58-71 (2017).

[7] Jeśman C., Młudzik A. and Cybulska M., History of antibiotics and sulphonamides discoveries, Pol. Merkur. Lekarski., 30(179), 320-322 (2011).

[8] Halpern S.R. and Cunningham J., bacteriologic and chemotherapeutic studies in acute diarrhea of infants and children. J Pediatr 21(2), 184-192 (1942).

[9] British Pharmacopoeia, London, pp. 1-374 (1988).

[10] United States Pharmacopoeia and National Formulary, Asian Edition, pp. 1564 (2000).

[11] Forti A.F. and Scortichini G, Determination of ten sulphonamides in egg by liquid chromatography-tandem mass spectrometry. Anal. Chim. Acta 637(1-2), 214-219 (2009).

[12] Gamba V., Terzano C., Fioroni L., Moretti S., Dusi G. and Galarini R., development and validation of a confirmatory method for the determination of sulphonamides in milk by liquid chromatography with diode array detection, Anal. Chim. Acta 637(1-2), 18-23 (2009).
[13] Ali A.M.M., Electroanalytical Studies of Azo Sulfa Drugs, Applications to novel heterocyclic sulfonamide azo dye, Anal. Lett. 26, 1635-1647 (1993).

[14] Flurer, C. L., Analysis of antibiotics by capillary electrophoresis, Electrophoresis, 18, 2427-2437 (1997).

[15] Siddappa K, Tambe M., Metre M. and Kote M., Spectrophotometric methods for the determination of sulfamethaxazole by a schiff's base reactions in pure and pharmaceutical dosage forms, Journal of Pharmacy Research 4(2), 308-311 (2011).

[16] Souza, C. D.; Braga, O. C.; Vieira, I. C.; Spinelli, A.; Electroanalytical determination of sulfadiazine and sulfamethoxazole in pharmaceuticals using a boron-doped diamond electrode. Sens. Actuators B 135(1), 66-73 (2008).

[17] Sanchez P. M., Salinas F., Mahedero M. C. and Aaron, J. J., Spectrofluorimetric determination of sulfonamides in pharmaceutical compounds and foods, J. Pharm. Biomed. Anal. 10, 805-808 (1992).

[18] Akl M. A. and Alharwi W. S. A., A green and simple technique for flotation and spectrophotometric determination of cobalt(II) in pharmaceutical and water samples, Egypt. J. Chem. 61(4), 639-650 (2018).

[19] Issa Y. M., Abdel-Fattah H. M. andAllahgi M. A. S., Spectrophotometric determination of benzethonium chloride using some chromotropic acid azo dyes, Egypt.J.Chem. 62, Special Issue (Part 1), 267 - 279 (2019).

[20] Nagaraja P., Yathirajan H. S., Raju C. R., Vasantha R. A., Nagendra P. and Hemantha Kumar M.S., 3-Aminophenol as a novel coupling agent for the spectrophotometric determination of sulfonamide derivatives, Il Farmaco 58, 1295-1300 (2003).

[21] Nagaraja P., Yathirajan H., Sunitha K. and Thapura R., A new, sensitive, and rapid spectrophotometric method for the determination of sulfa drugs, Journal of Aoac International 85(4), 869 (2002)

[22] Fogg A. G., Fayad N.M., Spectrophotometric and differential pulse polarographic determination of sulfaguanidine by reaction with hypochlorite and phenol, Anal. Chim. Acta 106, 365-367 (1979)

[23] Petrenko, V. V.; Spectrophotometric determination of some sulfanilamides with bindone [2,20-bis(indane-1,10,3,30tetrone)]. Zk. Anal. Khim. 35, 200-202 (1980).

[24] Mohamed A.M.I., Askal H.F. and Saleh G.A., Use of pBenzoquinone for the Spectrophotometric Determination of Certain Sulfonamides, J. Pharm. Biomed. Anal. 9, 531-538 (1991).

[25] Carmen A., Paula C, Isabel D. and Moises K., Application of experimental design to the development of a multicomponent derivative spectrophotometric method: Simultaneous determination of sulfathiazole and trimethoprim. Analyst 118 (1993) 1549-1553.

[26] Nagaraja S., Naik S., Shrestha A. and Shivakumar A., A sensitive spectrophotometric method for the determination of sulfonamides in pharmaceutical preparations, Acta Pharm. 57, 333-342 (2007).

[27] Nagaraja P., Sunitha, K. Vasantha R. and Yathirajan H., Iminodibenzyl as a novel coupling agent for the spectrophotometric determination of sulfonamide derivatives, European Journal of Pharmaceutics and Biopharmaceutics 53, 187-192 (2002)

[28] El-Ansary, A.L.; Abdel-Kader, N.S.; Asran, A.M. Spectrophotometric studies on the reaction of diaveridine with some sulfonphthalein dyes based on ion-pair/ion-associate complexes formation. Journal of Spectroscopy, Article ID 9269148 (2018).

[29] Benamor M. and Aguerssif N., Simultaneous determination of calcium and magnesium by derivative spectrophotometry in 
pharmaceutical products. Spectrochimica Acta Part A 69, 676-681 (2008).

[30] Markovic B., Ignjatovic J., Vujadinovic M., Savic V., Vladimirov S. and Katarina Karljikovic'-Rajic, Interlaboratory Verification of European Pharmacopoeia Monograph On Derivative Spectrophotometry Method And its Application for Chitosan Hydrochloride. Spectrochimica Acta Part A: Molecular and Biomolecular Spectroscopy 150, 792 798 (2015).

[31] Redasani V. K., Patel P. R., Marathe D. Y., Chaudhari S. R., Shirkhedkar A. A. and Surana S. J., A review on derivative UV-spectrophotometry analysis of drugs in pharmaceutical formulations and biological samples review, J. Chil. Chem. Soc. 63(3), 4126-4134 (2018).

[32] O,Haver T.C., Derivative and wavelength modulation spectrometry, Anal. Chem. 51 91A-100A (1979).

[33] Salinas F., Berzas-Nevado J.J. and Espinosa M.A., A new spectrophotometric method for quantitative multicomponent analysis resolution of mixtures of salicylic and salicyluric acids, Talanta, 37 (1990) 347-351.

[34] The European Agency for the Evaluation of Medical Products, ICH Topics Q2B Note for Guidance on Validation of Analytical procedures, Methodology CPMP/ICH/281/95, (1996).

[35] British Pharmacopoeia, HM Stationary Office, London, vol. 1, 432-439 (1980).

[36] Issa Y.M. and Hassib H.B., Conductimetric sudies of charge transfer complexes of some benzylidine aniline schiff bases with substituted pbenzoquinones, Egypt. J. Anal. Chem., 39(4), 329-338 (1996).

Egypt. J. Chem. 63, No. 10 (2020) 